\section{$\underset{\substack{\text { hommes } \\ \text { \& migrations }}}{ }$}

\section{Hommes \& migrations}

Revue française de référence sur les dynamiques

migratoires

1328 | 2020

Les réfugiés dans l'impasse

\title{
Stéphane Fière, La campagne n'est pas un jardin,
}

Phébus, Paris, 2019, 368 p., $20 €$.

\section{Mustapha Harzoune}

\section{(2) OpenEdition}

1 Journals

\section{Édition électronique}

URL : https://journals.openedition.org/hommesmigrations/11002

DOI : 10.4000/hommesmigrations. 11002

ISSN : 2262-3353

\section{Éditeur}

Musée national de l'histoire de l'immigration

\section{Édition imprimée}

Date de publication : 1 janvier 2020

Pagination : 217

ISBN : 978-2-919040-49-0

ISSN : 1142-852X

\section{Référence électronique}

Mustapha Harzoune, «Stéphane Fière, La campagne n'est pas un jardin, », Hommes \& migrations [En ligne], 1328 | 2020, mis en ligne le 01 janvier 2020, consulté le 03 janvier 2023. URL : http:// journals.openedition.org/hommesmigrations/11002 ; DOI : https://doi.org/10.4000/ hommesmigrations. 11002 


\section{La campagne n'est pas un jardin}

Stéphane Fière, Paris, Phébus, 2019, 368 pages, $20 €$.

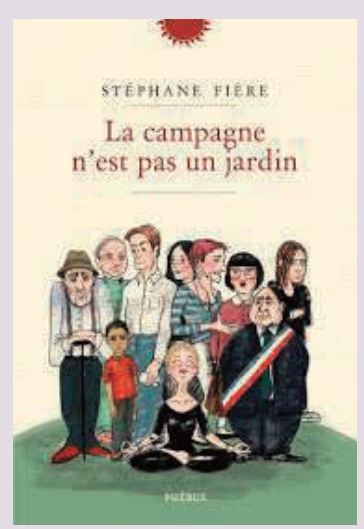

L'arrivée de migrants dans le quotidien d'une ville ou d'un village fait l'actualité. Mohamed Mbougar Sarr en avait fait l'objet de son roman Silence du Chœur (Présence africaine, 2017, Prix de la Porte Dorée). Stéphane Fière, à son tour, aborde la question: l'irruption d'un groupe de réfugiés dans un village paumé, d'une centaine d'habitants, perché à 1200 mètres d'altitude au fin fond de la Haute-Loire. Mais ici, il le fait du point de vue des villageois. L'émoi repose sur une décision de la préfecture de Doves, qui a choisi, sans concertations ni préparations, le village de Dorlange pour y installer des familles syriennes. Tel est le fil narratif du récit. Un fil extrêmement ténu - de migrants en chair et en os, il en est très peu question - qui traverse le récit de bout en bout, et autour duquel Stéphane Fière rapporte les discussions et oppositions, les positions, hostiles ou favorables, les doutes et les inquiétudes, les volontaires et les optimistes. Le cœur de cette histoire bat au rythme des réactions d'un village français plongé, malgré lui, dans le grand bain des migrations internationales. Avec une précision: Dorlange est déjà travaillé et transformé par d'autres migrations, par le grand bal des citadins et autre Hollandais qui viennent se refaire une santé à la campagne, sous le regard hostile ou indifférent des indigènes du cru, agriculteurs et autres chasseurs (souvent les mêmes). Les néo-ruraux ont débarqué. Ils sont tour à tour «intrus», «flanflans», "piouspious», «cassosses», «bobobéats», "choubabes», "antispécistes et vageans», «pétras» ou «alternatifs écologiques de carnaval décervelés par les apôtres de la décroissance», etc. Sur le sujet, Stéphane Fière est à son affaire. Ce sont les pages les plus écrites, les plus musclées et les plus drôles de ce roman. Il livre une sociologie précise, entre humour et acidité, des transformations à l'œuvre dans les campagnes françaises. Le monde rural de papa se meurt, "il faudrait accuser, dénoncer, stigmatiser, voter populiste, mais à quoi bon, la disparition est inéluctable». Et l'«intégration» des «flanflans» est d'autant moins aisée qu'ils se la pètent et la ramènent: "Dans les contrées qu'ils envahissent, les flanflans contestent tout ce qui organise la vie agricole depuis l'aube de l'humanité.»; "Entre eux et les locaux - les "AOC" occupant les lieux depuis des générations qui va l'emporter?»

Et puis le roman bascule, ou creuse le même sillon. Cette fois à partir de l'installation de quelques familles syriennes. Les uns se la jouent résistants contre l'envahisseur, les autres («nos» "flanflans») - souvent livrés à eux-mêmes - s'efforcent de soutenir l'aubain. Entre les deux, la préfecture magouille et manipule sans trop savoir à quelles fins (électoralistes sans doute). Au 
milieu de la confusion, il y a Antoine, le journaliste du coin, et Camille, la femme du cardiologue. D'origine libanaise par ses parents, elle assure tant bien que mal la traduction. Sur ses épaules repose la lourde tâche de créer du lien. La possibilité aussi d'écrire une nouvelle histoire à Dorlange. Cette seconde partie, consacrée aux manœurres des uns et des autres, s'articule autour de la relation extraconjugale entre le journaliste et l'épouse soumise. D'un côté, le retour au pays de l'enfant au cœur plusieurs fois brisé, de l'autre, une Bovary bien trop indécise. Finalement, il en sera de l'amour comme de l'hospitalité: «Mais, entend-on souvent, l'endroit de la médaille, la face positive de l'écu c'est l'arrivée des nouvelles populations dans le rural profond qui modifient la dynamique démographique et avec elle, le tissu social et professionnel???» Flanflans et réfugiés, même combat! Les roses de jardins ne poussent pas dans la campagne et il se pourrait que les ronces chassent toutes les opportunités.

M. $\mathrm{H}$. 